\title{
Probing Trends in Enantioinduction via Substrate Design: Palladium-Catalyzed Decarboxylative Allylic Alkylation of $a$ - Enaminones
}

\section{Douglas C. Duquette,}

The Warren and Katharine Schlinger Laboratory for Chemistry and Chemical Engineering, Division of Chemistry and Chemical Engineering, California Institute of Technology, Pasadena, California 91125, United States

\section{Alexander Q. Cusumano,}

The Warren and Katharine Schlinger Laboratory for Chemistry and Chemical Engineering, Division of Chemistry and Chemical Engineering, California Institute of Technology, Pasadena, California 91125, United States

\section{Louise Lefoulon,}

The Warren and Katharine Schlinger Laboratory for Chemistry and Chemical Engineering, Division of Chemistry and Chemical Engineering, California Institute of Technology, Pasadena, California 91125, United States

\section{Jared T. Moore,}

The Warren and Katharine Schlinger Laboratory for Chemistry and Chemical Engineering, Division of Chemistry and Chemical Engineering, California Institute of Technology, Pasadena, California 91125, United States

\section{Brian M. Stoltz}

The Warren and Katharine Schlinger Laboratory for Chemistry and Chemical Engineering, Division of Chemistry and Chemical Engineering, California Institute of Technology, Pasadena, California 91125, United States

\section{Abstract}

Herein, we report the palladium-catalyzed decarboxylative asymmetric allylic alkylation of $a$ enaminones. In addition to serving as valuable synthetic building blocks, we exploit the $a$ enaminone scaffold and its derivatives as probes to highlight structural and electronic factors that govern enantioselectivity in this asymmetric alkylation reaction. Utilizing the (S)-t-BuPHOX ligand in a variety of nonpolar solvents, the alkylated products are obtained in up to $99 \%$ yield and $99 \%$ enantiomeric excess.

\footnotetext{
Corresponding Author stoltz@ caltech.edu.

Complete contact information is available at: https://pubs.acs.org/10.1021/acs.orglett.0c01441

The authors declare no competing financial interest.

ASSOCIATED CONTENT

Supporting Information

The Supporting Information is available free of charge at https://pubs.acs.org/doi/10.1021/acs.orglett.0c01441.

Experimental procedures and characterization data (PDF)
} 


\section{Graphical Abstract}

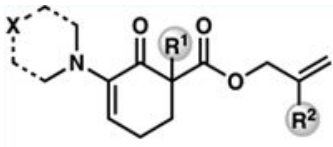

(土)

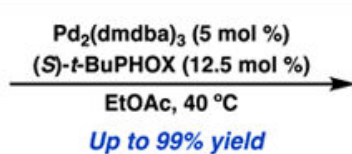

- Structural probe for enantioinduction

novel class of substrate

The development of the palladium-catalyzed decarboxylative asymmetric allylic alkylation reaction has been of longstanding interest in our group. ${ }^{1}$ With applications in fields ranging from total synthesis ${ }^{2}$ to pharmaceutical development, ${ }^{3}$ the allylic alkylation reaction has proven to be an enabling method for the asymmetric construction of all-carbon quaternary centers. ${ }^{1,4}$ Our initial disclosures showcased the chemistry in the context of carbocyclic ketone substrates to be utilized in this reaction (Figure 1). ${ }^{5}$ Employing the $(S)$ - $t$-BuPHOX (L1) ligand, enantioselectivities of the cyclic ketone products are generally limited to a maximum of $88-92 \%$ ee. In conjunction with the development of the electron-poor $(S)$ $\left(\mathrm{CF}_{3}\right)_{3}-t$-BuPHOX (L2) ligand, subsequent expansion of the substrate scope to include $N$ benzoyl lactams was realized. Interestingly, under these modified conditions, the alkylated lactam products are obtained in up to $99 \%$ ee. ${ }^{6}$ This finding represents a substantial improvement in enantioselectivity with respect to the carbocyclic ketone class of substrates.

Curious as to the origins of the enhanced reactivity and enantioselectivity of the N-benzoyl lactam substrate class, we sought to explore the underlying phenomenon through a hypothesis-driven approach to substrate design. Our approach is two-fold: (1) expand the scope of the reaction to include additional synthetically valuable substrates and (2) gain insight into the factors that dictate enantioselectivity and reactivity in the palladiumcatalyzed asymmetric allylic alkylation reaction.

In comparing the previously reported carbocyclic and $\mathrm{N}$-benzoyl lactam substrate classes, we note two potentially distinguishing features. First, assuming the intermediacy of a palladium-bound enolate, ${ }^{7}$ we hypothesize that the $\mathrm{N}$-functionalized lactams afford a more electron-rich enolate than the corresponding carbocyclic ketone analogues. The mechanism through which electrophilic alkylation occurs in canonical palladium-catalyzed Tsuji-Trost reactions is considered to be strongly influenced by the electronics of the nucleophile. ${ }^{8}$ Experiments suggest that alkylation of stabilized "soft" nucleophiles proceed through an outer-sphere attack of the electrophilic allyl species, ${ }^{9}$ whereas basic "hard" nucleophiles may undergo allylic alkylation via an inner-sphere process. ${ }^{10}$ Thus, modulating the electronics of the enolate may in turn affect the propensity for the $\mathrm{C}-\mathrm{C}$ bond-forming event to proceed through an inner-sphere or outer-sphere mechanism. Indeed, we believe that our prototypical asymmetric allylic alkylation proceeds via an inner-sphere-type mechanism. ${ }^{11}$

To probe the hypothesis that an increasingly basic palladium enolate is driving the enhanced enantioselectivity of the lactam substrates, we previously investigated $\beta$-enaminones (i.e., vinylogous amides) as electron-rich surrogates for the carbocyclic ketone substrate. ${ }^{12}$ Interestingly, these vinylogous amides maintain reactivity and selectivity comparable to that 
of typical ketone substrates, with enantioselectivities ranging from 52 to $90 \%$ ee but not greater than $90 \%$ ee.

In addition to perturbation of the electronics of the hypothesized palladium enolate, we considered potential chelation of the Lewis basic oxygen atom of the benzoyl lactam to the palladium center in a palladium-bound enolate. In lieu of a clear trend between enolate electronics and enantioselectivity, we sought to further explore this second hypothesis through design of a carbocyclic class of substrates bearing a Lewis basic heteroatom in the $a$ '-position. Simultaneously considering synthetic utility of such a substrate class lead us to $a$-enaminones (i.e., 1).

To our delight, morpholine-containing allyl $\beta$-ketoester 1a affords the desired product $2 \mathbf{a}$ in quantitative yield and $95 \%$ ee under our previously reported conditions with $\mathbf{L} 2$ (entry 9 ) in THF. Subsequent screening of reaction conditions reveals that enantioselectivity is a largely invariant solvent choice, and similar results are even obtained with the standard $(S)$ - $t$ BuPHOX (L1) ligand in a variety of nonpolar solvents (Table 1). Given this, we selected ethyl acetate as an inexpensive, readily available, and environmentally benign solvent for use in subsequent development.

We then sought to explore the scope of the transformation across a variety of substitution patterns. Both yield and enantioselectivity are maintained across various $\boldsymbol{a}$-substituents (Table 2). Interestingly, 2-methyl and 2-chloroallyl fragments also afford the desired product with high enantioselectivity, albeit with reduced yield in the 2-methyl case. It is worth noting that substitution at the 1 or 3 positions of the allyl group is not tolerated under these conditions. As previously mentioned, $a$-enaminones $\mathbf{2 a}-\mathbf{l}$ represent the first carbocyclic substrate class to achieve of enantioselectivities of up to $99 \%$ ee in this asymmetric allylic alkylation.

We then sought to probe further structural modifications to the carbocyclic backbone of the enolate fragment (Table 3). Piperidene-containing product $\mathbf{2} \mathbf{m}$ was obtained in $99 \%$ yield and $99 \%$ ee, suggesting the distal oxygen of the morpholine ring is not critical for enantioinduction. Introduction of a $\beta$-methyl group to the enaminone affords a more sluggish reaction and reduced yield, whereas enantioselectivity is only slightly diminished (2n). ${ }^{13}$ We then aimed to explore the role of the potentially coordinating $a$-amine through cyclohexyl substrate $1 \mathrm{o}$. In accordance with our working hypothesis, product $2 \mathrm{o}$ was obtained in high yield (93\%) but with reduced enantioselectivity (72\% ee). Considering the possibility of $a$-nitrogen chelation, we aimed to explore the effects of perturbations in the $\mathrm{N}$ $-\mathrm{Pd}-\mathrm{O}$ bite angle by preparing an analogous five-membered cyclic $a$-enaminone substrate, 1p. Under the optimized reaction conditions, substrate $\mathbf{1 p}$ affords the desired product $\mathbf{2 p}$ in 94\% yield and a reduced $83 \%$ ee.

Thus far, the trends in observed product enantioenrichment with respect to substrate modification are qualitatively consistent with the proposition that enhancement in enantioselectivity of the allylic alkylation reaction may arise from secondary chelation of $a$ heteroatoms to the metal center in the hypothesized palladium enolate. However, we note 
that these are only observations, and a thorough mechanistic study will be required to delineate the potentially numerous factors that influence enantioselectivity.

We next turned our attention to investigating the synthetic utility of the chiral quaternarycenter-containing $a$-enaminone products for access to potential synthetic building blocks. Treatment of enaminone $\mathbf{2 a}$ with hydrochloric acid in a methanol-water mixture revealed the latent 1,2-diketone functionality, providing compound 3 in $72 \%$ yield. Unfortunately, the analogous reaction of $\mathbf{2 a}$ with aniline and catalytic tosic acid in toluene affords the transaminated product $\mathbf{4}$ in only modest 35\% yield. However, $\mathbf{2 a}$ is a competent substrate for Fisher indolization, providing indole $\mathbf{5}$ in nearly quantitative yield (over two steps). 2Morpholine-substituted enaminones have also been utilized as precursors to pyrazole-based inhibitors of blood coagulation factor Xa by reaction with $p$ methoxyphenylchlorohydrazones. ${ }^{14}$ Accordingly, when treated with methyl (Z)-2chloro-2-(2-(4-methoxyphenyl)-hydrazineylidene)acetate, enaminone 2a yields the corresponding pyrazole 6 in $46 \%$ yield (Scheme 1). Further functionalization at the $\beta$ position of enaminone 2a may be achieved through an electrophilic bromination with NBS and subsequent Suzuki-Miyaura cross-coupling with phenyl boronic acid, affording compound 7 in $58 \%$ yield over two steps.

In conclusion, we present $\boldsymbol{a}$-enaminones as a new substrate class for the palladium-catalyzed decarboxylative allylic alkylation. Product yields of up to $99 \%$ and enantioselectivities of up to $99 \%$ ee are achieved. The quaternary-center-containing enaminone products are demonstrated to be competent precursors in a variety of postalkylation synthetic transformations. In addition to serving as useful synthetic building blocks, the $a$-enaminone substrate class and its derivatives offer new insight into the potential role of $a$-heteroatom chelation for general enhancement of enantioselectivities for the palladium-catalyzed allylic alkylation reaction. Studies to elucidate the effect of these coordinating groups are currently in progress.

\section{Supplementary Material}

Refer to Web version on PubMed Central for supplementary material.

\section{ACKNOWLEDGMENTS}

We thank the NIH-NIGMS (R01GM080269), and the NSF (predoctoral research fellowship to D.C.D., No. DGE-1144469) for financial support. Research reported in this publication was supported by the NIH-NIGMS under Award Number F32GM116304 (postdoctoral fellowship to J. T. Moore). We further thank Dr. Scott C. Virgil (Caltech) for assistance with chiral-SFC separation and insightful discussion.

\section{REFERENCES}

(1). Liu Y; Han S-J; Liu W-B; Stoltz BM Acc. Chem. Res 2015, 48 (3), 740-751. [PubMed: 25715056]

(2). For examples in recently reported syntheses, see:(a)Stoltz BM; Pritchett BP; Kikuchi J; Numajiri Y Heterocycles 2017, 95 (2), 1245. [PubMed: 28706345] (b)Kim KE; Stoltz BM Org. Lett 2016, 18 (21), 5720-5723. [PubMed: 27762136] (c)Pritchett BP; Donckele EJ; Stoltz BM Angew. Chem., Int. Ed 2017, 56 (41), 12624-12627.(d)Pritchett BP; Stoltz BM Nat. Prod. Rep 2018, 35 (6), 559-574. [PubMed: 29658039] (e)Loskot SA; Romney DK; Arnold FH; Stoltz BM J. Am. 
Chem. Soc 2017, 139 (30), 10196-10199. [PubMed: 28721734] (f)Defieber C; Mohr JT; Grabovyi GA; Stoltz BM Synthesis 2018, 50 (22), 4359-4368. [PubMed: 31061542] (g)Hartrampf N; Winter N; Pupo G; Stoltz BM; Trauner D J. Am. Chem. Soc 2018, 140 (28), 8675-8680. [PubMed: 29889502]

(3). Sun AW; Bulterys PL; Bartberger MD; Jorth PA; O'Boyle BM; Virgil SC; Miller JF; Stoltz BM Bioorg. Med. Chem. Lett 2019, 29 (18), 2686-2689. [PubMed: 31383589]

(4). (a)Trost BM; Jiang C Synthesis 2006, 3, 369-396.(b)James J; Guiry PJ ACS Catal. 2017, 7, 13971402.(c)Jackson M; O’Broin CQ; Müller-Bunz H; Guiry PJ Org. Biomol. Chem 2017, 15, 8166 8178. [PubMed: 28920985] (d)Akula R; Guiry PJ Org. Lett 2016, 18, 5472-5475. [PubMed: 27780358] (e)Akula R; Doran R; Guiry PJ Chem. - Eur. J 2016, 22, 9938-9942. [PubMed: 27191198] (f)Tunge JA Isr. J. Chem 2020, 60, 351-359.

(5). (a)Behenna DC; Stoltz BM J. Am. Chem. Soc 2004, 126 (46), 15044-15045. [PubMed: 15547998] (b)Mohr JT; Behenna DC; Harned AM; Stoltz BM Angew. Chem., Int. Ed 2005, 44 (42), 6924-6927.

(6). Behenna DC; Liu Y; Yurino T; Kim J; White DE; Virgil SC; Stoltz BM Nat. Chem 2012, 4 (2), 130-133.

(7). (a)Keith JA; Behenna DC; Mohr JT; Ma S; Marinescu SC; Oxgaard J; Stoltz BM; Goddard WA J. Am. Chem. Soc 2007, 129 (39), 11876-11877. [PubMed: 17824701] (b)Keith JA; Behenna DC; Sherden N; Mohr JT; Ma S; Marinescu SC; Nielsen RJ; Oxgaard J; Stoltz BM; Goddard WA J. Am. Chem. Soc 2012, 134 (46), 19050-19060. [PubMed: 23102088]

(8). (a)Trost BM; Thaisrivongs DA J. Am. Chem. Soc 2008, 130 (43), 14092-14093. [PubMed: 18826305] (b)Zhang K; Peng Q; Hou X-L; Wu Y-D Angew. Chem., Int. Ed 2008, 47 (9), 17411744.(c)Trost BM; Xu J; Schmidt T J. Am. Chem. Soc 2009, 131 (51), 18343-18357. [PubMed: 19928805]

(9). Trost BM; Verhoeven TR J. Org. Chem 1976, 41 (19), 3215-3216.

(10). Matsushita H; Negishi E J. Chem. Soc., Chem. Commun 1982, 3, 160-161.

(11). Sherden NH; Behenna DC; Virgil SC; Stoltz BM Angew. Chem., Int. Ed 2009, 48 (37), 68406843.

(12). Bennett NB; Duquette DC; Kim J; Liu W-B; Marziale AN; Behenna DC; Virgil SC; Stoltz BM Chem. - Eur. J 2013, 19 (14), 4414-4418. [PubMed: 23447555]

(13). The recovered starting material $(1 \mathrm{~m})$ ofthis reaction was isolated in $18 \%$ yield and $99 \%$ ee. When the reaction was stopped at $12 \mathrm{~h}$, the recovered starting material was obtained in $75 \%$ yield and $16 \%$ ee. This corresponds to a modest s value of 3.3. These data indicate a small but notable relative preference for one enantiomer of the starting material as a substrate for the stereoablative decarboxylation beginning the catalytic cycle of the reaction, which to our knowledge is only observed in this specific substrate. In other cases, we have studied that there is indiscernible kinetic resolution of the starting allyl esters.

(14). Pinto DJP; Orwat MJ; Koch S; Rossi KA; Alexander RS; Smallwood A; Wong PC; Rendina AR; Luettgen JM; Knabb RM; He K; Xin B; Wexler RR; Lam PYS J. Med. Chem 2007, 50 (22), 5339-5356. [PubMed: 17914785] 
a)<smiles>C=CCOC(=O)C1(C)CCCCC1=O</smiles>

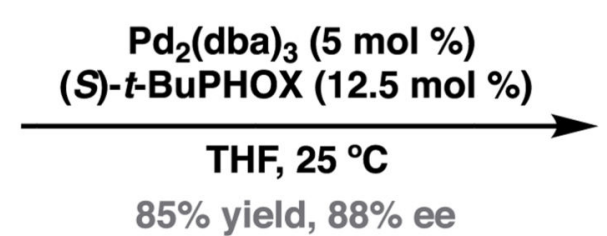<smiles>C=CC[C@]1(C)CCCCC1=O</smiles>

b)<smiles>C=CCOC(=O)C1(C)CCCN(C(=O)c2ccccc2)C1=O</smiles>
(S)- $\left(\mathrm{CF}_{3}\right)_{3}$-t-BuPHOX (12.5 mol \%) toluene, $40{ }^{\circ} \mathrm{C}$ $99 \%$ yield, $99 \%$ ee<smiles>C=CC[C@]1(C)CCCN(C(=O)c2ccccc2)C1=O</smiles>

c)<smiles>[R]N(Cc1ccccc1)C1=CC(=O)[C@](C)(CC=C)CC1</smiles>

Electron-rich enolate $52-90 \%$ ee<smiles>CC1CCCC1</smiles>

$\mathrm{Ph}^{-}$<smiles>C=CC[C@]1(C)CCCN(C(=O)c2ccccc2)C1=O</smiles>

\section{Potential substrate chelation} Electron-rich enolate 99\% yield, $99 \%$ ee

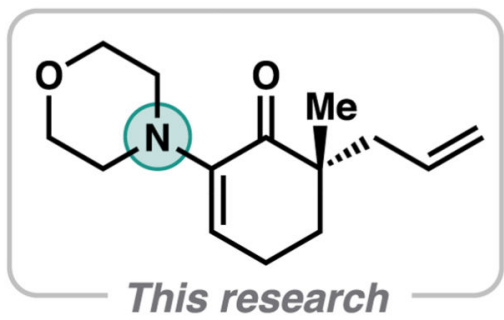

Potential substrate chelation 92-99\% ee

Figure 1.

(a) Previous report of allylic alkylation in the context of carbocyclic allyl $\beta$-ketoesters. ${ }^{5 \mathrm{a}}$ (b) Extension of the methodology to $N$-benzoyl lactams. ${ }^{6}$ (c) Hypothesis-driven substrate design presented herein. 


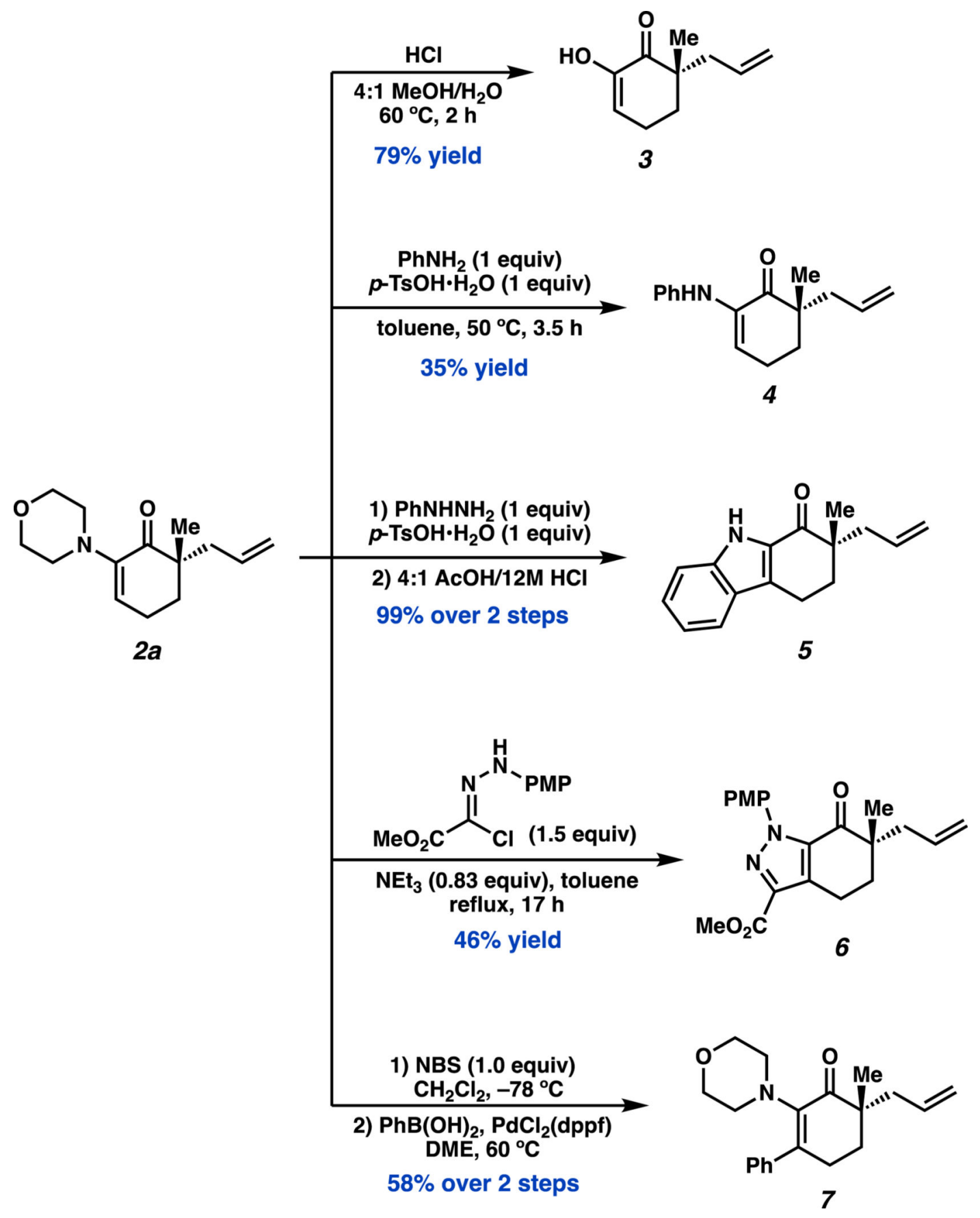

Scheme 1.

Enaminone Product Transformations 
Table 1.

Solvent and Ligand Screen for the Enantioselective Decarboxylative Allylic Alkylation of Enaminone $1 \mathrm{a}^{a}$

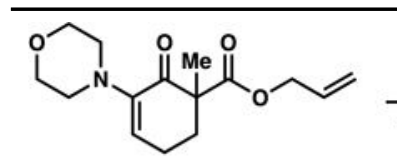

( \pm -1a

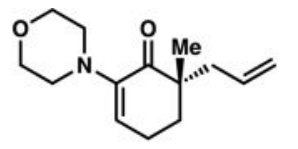

(S)-2a

\begin{tabular}{|c|c|c|c|c|c|c|c|}
\hline entry & ligand & solvent & ee $(\%)^{b}$ & entry & ligand & solvent & ee $(\%)^{b}$ \\
\hline 1 & L2 & MeCN & 88 & 8 & $L 2$ & toluene & 97 \\
\hline 2 & $L 2$ & dioxane & 94 & 9 & $L 2$ & EtOAc & 98 \\
\hline 3 & $L 2$ & THF & 95 & 10 & $L 2$ & i-PrOAc & 96 \\
\hline 4 & L2 & 2-MeTHF & 96 & 11 & L2 & i-BuOAc & 92 \\
\hline 5 & $L 2$ & $\mathrm{Et}_{2} \mathrm{O}$ & 97 & 12 & $L 1$ & EtOAc & 98 \\
\hline 6 & L2 & DME & 95 & 13 & $L 1$ & toluene & 94 \\
\hline
\end{tabular}

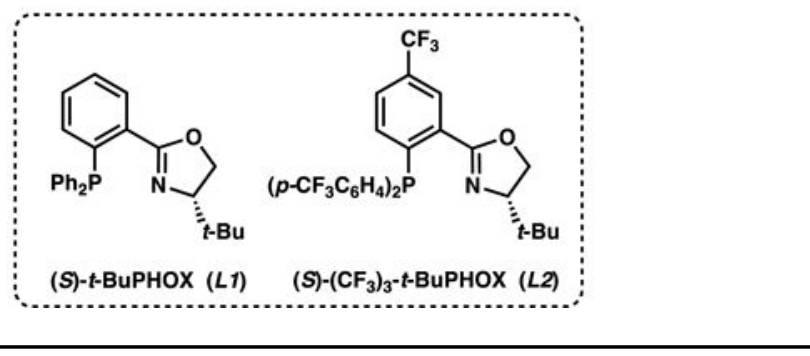

${ }^{a}$ Conditions: $\beta$-ketoester $(0.05 \mathrm{mmol}), \mathrm{Pd}_{2}(\mathrm{dmdba}) 3(5.0 \mathrm{~mol} \%)$, ligand $(12.5 \mathrm{~mol} \%)$, solvent $(1.5 \mathrm{~mL}), 40{ }^{\circ} \mathrm{C}, 12 \mathrm{~h}$.

${ }^{b}$ Determined by analytical chiral SFC. See Supporting Information for details.

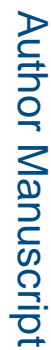

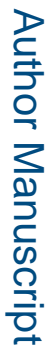

Org Lett. Author manuscript; available in PMC 2021 July 02. 
Table 2.

Substrate Scope of the Enantioselective Decarboxylative Allylic Alkylation of Enaminones ${ }^{a}$

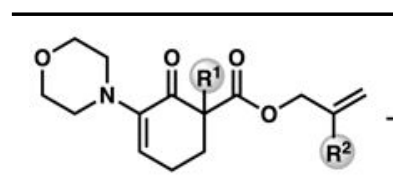

(土)-1

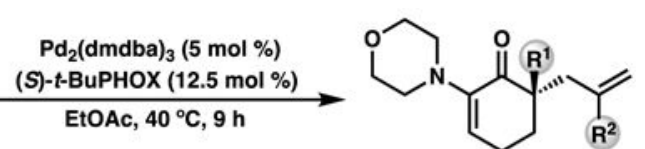

(S)-2

\begin{tabular}{|c|c|c|c|c|c|}
\hline entry & product & $\mathbf{R}^{1}$ & $\mathbf{R}^{2}$ & yield $(\%)^{b}$ & ee $(\%)^{c}$ \\
\hline 1 & $2 a$ & $\mathrm{Me}$ & $\mathrm{H}$ & $95(93)^{d}$ & $99(98)^{d}$ \\
\hline 2 & $2 b$ & Et & $\mathrm{H}$ & 99 & 98 \\
\hline 3 & $2 c$ & $\mathrm{CH}_{2} \mathrm{OTBS}$ & $\mathrm{H}$ & 96 & 99 \\
\hline 4 & $2 d$ & $\mathrm{CH}_{2} \mathrm{CH}_{2} \mathrm{OTBS}$ & $\mathrm{H}$ & 93 & 99 \\
\hline 5 & $2 \mathrm{e}$ & $\mathrm{CH}_{2} \mathrm{CH}_{2} \mathrm{CO}_{2} \mathrm{Me}$ & $\mathrm{H}$ & 98 & 97 \\
\hline 6 & $2 f$ & $\mathrm{CH}_{2} \mathrm{CH}_{2} \mathrm{C}(\mathrm{O}) \mathrm{Me}$ & $\mathrm{H}$ & 90 & 94 \\
\hline 7 & $2 \mathrm{~g}$ & $\mathrm{CH}_{2} \mathrm{CH}_{2} \mathrm{CN}$ & $\mathrm{H}$ & 99 & 94 \\
\hline 8 & $2 \mathrm{~h}$ & $\mathrm{Bn}$ & $\mathrm{H}$ & 95 & 96 \\
\hline 9 & $2 \mathbf{i}$ & $p$-(OMe $) \mathrm{Bn}$ & $\mathrm{H}$ & 99 & 95 \\
\hline 10 & $2 j$ & $p-\left(\mathrm{CF}_{3}\right) \mathrm{Bn}$ & $\mathrm{H}$ & 87 & 92 \\
\hline 11 & $2 \mathbf{k}$ & $\mathrm{Me}$ & $\mathrm{Me}$ & 92 & 99 \\
\hline 12 & 21 & $\mathrm{Me}$ & $\mathrm{Cl}$ & 58 & 99 \\
\hline
\end{tabular}

${ }^{a}$ Conditions: $\beta$-ketoester $(0.47 \mathrm{mmol}), \mathrm{Pd} 2(\mathrm{dmdba}) 3(5.0 \mathrm{~mol} \%),(S)$ - $t$-BuPHOX $(12.5 \mathrm{~mol} \%)$, EtOAc $(14 \mathrm{~mL}), 40{ }^{\circ} \mathrm{C}, 9 \mathrm{~h}$.

$b_{\text {Isolated yield. }}$

$c$ Determined by analytical chiral SFC. See Supporting Information for details.

${ }^{d}$ Conditions: $\beta$-ketoester $(12.3 \mathrm{mmol}), \mathrm{Pd}_{2}(\mathrm{dmdba}) 3(0.5 \mathrm{~mol} \%),(S)-t$-BuPHOX $(1.3 \mathrm{~mol} \%), \operatorname{EtOAc}(37 \mathrm{~mL}), 40{ }^{\circ} \mathrm{C}$.

Org Lett. Author manuscript; available in PMC 2021 July 02. 
Table 3.

Further Structural Variation of Enaminone ${ }^{a}$
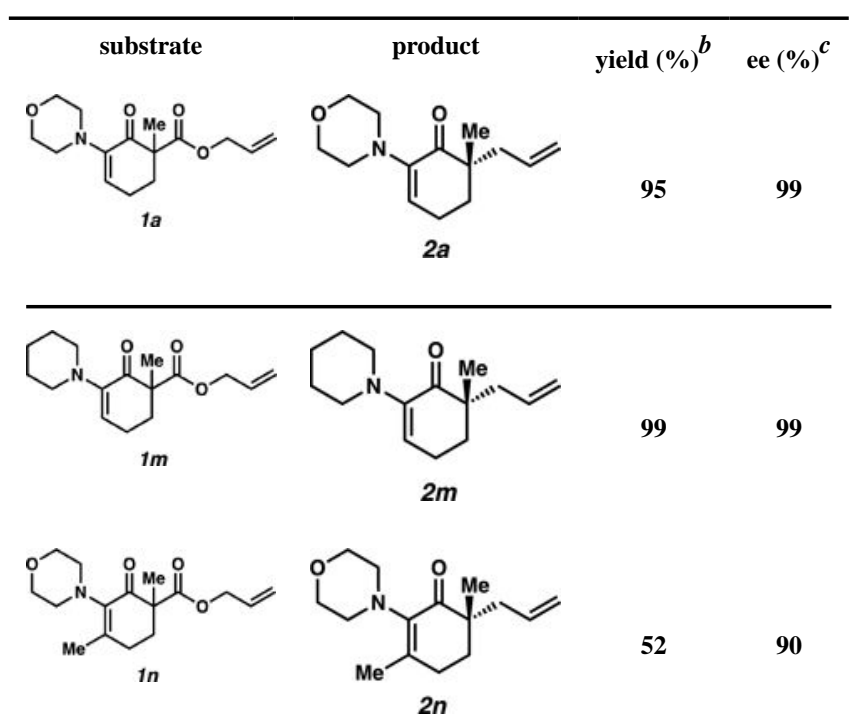

5290
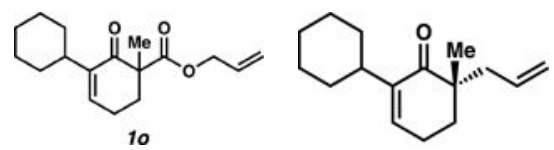

20

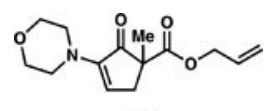

$1 p$

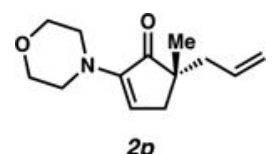

94

83

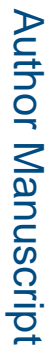

${ }^{a}$ Conditions: $\beta$-ketoester $(0.47 \mathrm{mmol}), \mathrm{Pd}_{2}(\mathrm{dmdba}) 3$ (5.0 mol \%), $(S)-t$-BuPHOX (12.5 mol \%), EtOAc $(14 \mathrm{~mL}), 40{ }^{\circ} \mathrm{C}$.

$b_{\text {Isolated yield. }}$

${ }^{c}$ Determined by analytical chiral SFC. See Supporting Information for details. Values in red highlight deviations from those of model substrate $\mathbf{2 a}$. 